\title{
Truth Be Told: Evidence of Wheelchair Users' Accuracy in Reporting Their Height and Weight
}

\author{
Katherine Froehlich-Grobe, PhD, Dorothy E. Nary, PhD, Angela VanSciver, BA, Richard A \\ Washburn, PhD, and Lauren Aaronson, RN, PhD, FAAN \\ From the University of Texas School of Public Health, Dallas Regional Campus, Dallas, TX \\ (Froehlich-Grobe); Research and Training Center on Independent Living, LifeSpan Institute, \\ University of Kansas, Lawrence, KS (Nary); and University of Kansas Medical Center, Kansas \\ City, KS (VanSciver, Washburn, Aaronson)
}

\begin{abstract}
Objectives-To examine whether wheelchair users' self-reports of height and weight differed significantly from direct measurements and whether weight category classifications differed substantially when based on self-reported or measured values.
\end{abstract}

Design-Single group, cross-sectional analysis. Analyses included paired $t$ tests, chi-square test, analysis of variance, and Bland-Altman agreement analyses.

Setting-A university-based exercise lab.

Participants-Community-dwelling wheelchair users ( $\mathrm{N}=125)$.

Interventions-Not applicable.

Main Outcome Measure-Participants' self-reported and measured height, weight, and body mass index.

Results-Paired $t$ tests revealed that there were significant differences between wheelchair users' self-reported and measured values for height (difference of $3.1 \pm 7.6 \mathrm{~cm} \mathrm{[1.2 \pm 3.0in]),} \mathrm{weight}$ $(-1.7 \pm 6.5 \mathrm{~kg}[-3.6 \pm 14.2 \mathrm{lb}])$, and BMI $(-1.6 \pm 3.3)$. These discrepancies also led to substantial misclassification into weight categories, with reliance on self-reported BMI underestimating the weight status of $20 \%$ of the sample.

Conclusions-Our findings suggest that similar to the general population, wheelchair users are prone to errors when reporting their height and weight and that these errors may exceed those noted in the general population.

\section{Keywords}

Obesity; Overweight; Public health; Rehabilitation

\footnotetext{
(C) 2012 by the American Congress of Rehabilitation Medicine

Correspondence to Katherine Froehlich-Grobe, PhD, University of Texas School of Public Health, Dallas Regional Campus, 6011 Harry Hines Blvd, V8.112, Dallas, TX 75390, katherine.froehlich-grobe@utsouthwestern.edu.

Clinical Trial Registration No.: NCT00866112.

Reprints are not available from the author.

No commercial party having a direct financial interest in the results of the research supporting this article has or will confer a benefit on the authors or on any organization with which the authors are associated.
} 
The obesity epidemic in the United States and other industrialized nations ${ }^{1,2}$ requires urgent action because of the increased risk for disease and early death. In the United States, several national surveys (Behavioral Risk Factor Surveillance System, National Health Interview Survey, and the National Health and Nutrition Examination Survey) track obesity prevalence using respondents' height and weight to calculate their body mass index (BMI) (weight in kg divided by height in $\mathrm{m}^{2}$ ), which is then associated with a weight category (healthy, overweight, and obese following the National Heart, Lung, and Blood Institute designated cut points). ${ }^{4}$ Use of BMI allows efficient and less expensive population-level data collection, because it typically relies on self-reported height and weight. ${ }^{4,5}$

Yet, people tend to overestimate their height and underestimate their weight, ${ }^{5-7}$ which contributes to errors in calculating BMI when based on self-report, ${ }^{7-9}$ and results in lower estimates of overweight and obesity prevalence. While the average reporting errors for height and weight across studies are typically small (height overestimates range, $0.6-7.5 \mathrm{~cm}$; weight underestimates range, $0.6-3.5 \mathrm{~kg}$ ), individuals with BMIs greater than 30 report greater discrepancies in weight (underestimated by $3-6 \mathrm{~kg}$ ) ${ }^{8,10}$ Further, discrepancies between measured and self-report values differ based on racial and demographic factors, such as age, BMI values, sex, and ethnicity/race. ${ }^{11-13}$ Errors in reporting height and weight are not unique to U.S. residents, because reporting errors have also been documented among Dutch overweight working persons ${ }^{14}$ and Canadian adults and adolescents. ${ }^{15}$

National data suggest that people with disabilities have significantly higher obesity rates than those observed in the general population, ${ }^{16-18}$ and obesity rates are highest among those with lower extremity mobility impairment. ${ }^{16}$ Notably, current prevalence estimates for people with disabilities derive exclusively from self-reported height and weight. Given consistent evidence of people's tendency to inaccurately report their height and weight, people with disabilities are likely to also be inaccurate reporters. However, to our knowledge, there have been no studies examining agreement between measured and selfreported height and weight for people with disabilities, including those with mobility impairments (eg, wheelchair users). Among factors associated with reporting accuracy in the general population, those who weigh themselves less often are less accurate at reporting weight. ${ }^{14}$ This issue is particularly relevant for wheelchair users. Primary care practices have limited availability of wheelchair accessible scales ${ }^{19}$ and such scales also are cost prohibitive for home use.

Evidence also suggests that wheelchair users overestimate their height, ${ }^{20,21}$ likely because of the fact that many wheelchair users are unable to stand for measurement with a stadiometer. Given the strong association between obesity and health problems, it is important to identify whether wheelchair users similarly err in reporting their height and weight, and whether their discrepancies are larger than those observed among other groups. If people with disabilities in general, and wheelchair users in particular, are as prone to similar or greater reporting errors in height and weight as the general population, ${ }^{9}$ obesity prevalence may be greater among people with disabilities than previously estimated.

Therefore, the purpose of this article is to compare self-reported height and weight with measured height and weight of wheelchair users to determine if there are discrepancies between the measurement methods and to determine whether BMI differs based on selfreported versus measured values.

\section{METHODS}

Data for this study were collected as part of a large randomized controlled trial designed to examine the effectiveness of a multicomponent behavioral program to promote exercise 
adoption and maintenance by wheelchair users. The methods of participant recruitment for the larger trial were previously published, ${ }^{22}$ but generally included disseminating study brochures through medical provider offices and through media venues such as direct mailing, radio, and newspapers. Interested participants called the study staff to learn about the study details and to be screened for eligibility, which included receipt of signed approval by the individuals' primary physician. Eligibility criteria included: mobility impairment for $\succeq 6$ months that necessitates manual or powered wheelchair use for mobility outside of the home; aged between 18 and 65 years; not currently physically active (report $<150 \mathrm{~min}$ of exercise a week); sufficient upper arm mobility for aerobic exercise; and physician consent to exercise.

Exclusion criteria included: BMI of 250 ; medical conditions such as chronic obstructive pulmonary disease, liver or kidney disease, or cardiac problems that their physician identifies as a contraindication for participating in unsupervised exercise; and pregnancy, or planning to become pregnant.

\section{Assessments}

Participants' height and weight were measured at the exercise lab of the General Clinical Research Center of the University of Kansas Medical Center. Participants were instructed to wear light, comfortable clothing. Participant weight was measured using a seca wheelchair accessible scale (seca \#664). ${ }^{\mathrm{a}}$ After the initial weight was obtained, participants transferred from their wheelchair onto a mat table and their wheelchair was weighed. Participants' body weight was derived by subtracting the wheelchair weight from the combined weight of the body and wheelchair.

Based on a previous study of the most accurate method to measure height among wheelchair users ${ }^{20}$ we used participants' measured recumbent height to calculate BMI. Height was measured with the participant lying supine on a mat table using a custom-made anthropometer. The anthropometer components included 2 adjustable T squares, ${ }^{23} 4$ wooden blocks, and 2 metal plates. Wooden blocks secured the two $121.92 \mathrm{~cm}$ (48-in) rulers with screws, permitting the ruler to slide open for measuring lengths between 121.92 and $215.9 \mathrm{~cm}(48-85 \mathrm{in})$, with a metal plate affixed to the inside edge at each end (fig 1). One metal plate of the anthropometer was placed against the top of the participant's head and the ruler ran along the right side of the participant's body. Participants were instructed to use their right hand to hold the metal plate against the top of their head to assure the plate remained in contact with the top of their head. With the right leg aligned with the hip, the edge of the tool was placed on the distal end of the calcaneous of the participant's right foot. For those with spasticity, contractures, or inability to lay flat or dorsiflex their ankle to $90^{\circ}$, staff manually assisted in extending the leg as far as possible or dorsiflexing the ankle. Height was recorded to the nearest 1/16 of an inch (reported in $\mathrm{cm}$ ).

\section{Analyses}

Means and frequencies were calculated for demographic data, BMI, and weight categories. Chi-square analyses assessed whether there were significant differences across weight category distributions for BMI based on self-reported and measured values. Paired $t$ tests examined whether there were significant differences between participants' self-reported and measured values for height, weight, and BMI. Analyses of variance (ANOVAs) assessed whether there were significant differences by weight category (under/healthy, overweight, or obese) in reporting errors for height and weight. Bland and Altman ${ }^{24}$ agreement analyses were included to visually inspect the extent of agreement between self-reported and

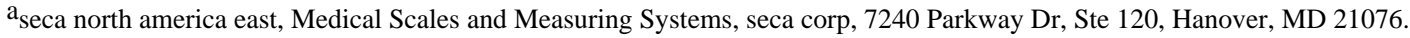


measured height and weight. All results in the tables are presented in metric units, but to facilitate interpretation we included U.S. standard units in the text.

\section{RESULTS}

Participants' demographic characteristics are presented in table 1. The sample included nearly equal numbers of middle-aged, predominantly white men and women, who on average, had lived 22 years with their mobility impairment. The primary causes of disability were spinal cord/traumatic brain injury and spina bifida/cerebral palsy ( $\sim 7 \%$ of the sample). Participants reported having their weight last measured over 1.5 years before, during a hospital $(47.4 \%)$ or physician clinic visit (35.3\%); only $6 \%$ reported being weighed at home. Chi-square analyses revealed significant differences in weight categories between measured and self-reported values $\left(\chi^{2} 4,125=100.97, P=.000\right)$. Direct weight assessments indicated that $26 \%$ of the sample was overweight and $47 \%$ were obese, while self-reported measures indicated that $24 \%$ were overweight and $40 \%$ were obese. These data may underestimate the proportion of extreme (or morbid) obesity because of the exclusion criterion (BMI 250) for the parent study, as 14 individuals (of 323 screened) were excluded for this reason.

Measured values were compared with self-reported values for height and weight for the overall sample and by sex (table 2). Wheelchair users significantly overestimated their height and underestimated their weight, resulting in significantly lower BMIs when compared with measured values. Reporting errors varied by sex. Men significantly overestimated their height by $3.6 \pm 7.1 \mathrm{~cm}(1.4 \pm 2.8 \mathrm{in})(P=.000)$, but the difference between self-reported and measured weight in men $(.54 \pm 7.4 \mathrm{~kg}[-1.2 \pm 16.4 \mathrm{lb}])$ was not statistically significant $(P=.566)$. Women significantly overestimated their height by $2.6 \pm 8.1 \mathrm{~cm}$ $(1.0 \pm 3.1 \mathrm{in})(P=.013)$ and significantly underestimated their weight $2.7 \pm 5.1 \mathrm{~kg}(6.1 \pm 11.2 \mathrm{lb})$ $(P=.000)$.

The ANOVA results revealed that reporting errors for height did not differ by weight category for either men or women (table 3 ). In contrast, we observed significant differences between self-reported and measured weight across weight categories for both men $(P=.020)$ and women $(P=.025)$. Obese men and overweight and obese women underestimated their weight by averages of $2.9 \pm 6.0 \mathrm{~kg}, 4.2 \pm 4.3 \mathrm{~kg}, 3.5 \pm 6.1 \mathrm{~kg}(6.1 \pm 13.3 \mathrm{lb}, 9.3 \pm 9.5 \mathrm{lb}$, and $7.8 \pm 13.4 \mathrm{lb})$, respectively, while healthy weight men overestimated their weight $(3.2 \pm 9.1 \mathrm{~kg}$ $[7.0 \pm 20.1 \mathrm{lb}])$ and healthy weight women and overweight men offered more accurate estimates $(0.1 \pm 2.2 \mathrm{~kg}[.23 \pm 4.8 \mathrm{lb}]$ and $0.2 \pm 6.2 \mathrm{~kg}[-.47 \pm 13.6 \mathrm{lb}]$, respectively).

Bland-Altman agreement analyses (figs 2-5) revealed that a large proportion of participants overestimated their height $(\mathrm{men}=76.2 \%$, women $=64.5 \%)$ and underestimated their weight $(m e n=61.9 \%$, women $=66.1 \%)$. Notably, the limits of agreement for height were wide for both men ( -10.6 to $17.8 \mathrm{~cm}$ [ -4.1 to $6.9 \mathrm{in}])$ and women ( -13.5 to $18.7 \mathrm{~cm}$ [ -5.3 to $7.3 \mathrm{in}])$, as were the limits of agreement for weight for both men ( -15.4 to $14.3 \mathrm{~kg}$ [ -33.9 to $31.5 \mathrm{lb}])$ and women (-13.0 to $7.4 \mathrm{~kg}$ [ -28.6 to $16.3 \mathrm{lb}])$. Further, a sizeable portion of the sample $(12.8 \%)$ made self-report errors for height that exceeded $\pm 5 \%$, with $11.2 \%$ overestimating their height an average of $17.6 \pm 10.8 \mathrm{~cm}(6.9 \pm 4.2 \mathrm{in})$. Self-report errors for weight exceeded $\pm 5 \%$ for more than half the men $(53.1 \%)$ and over one third (39.1\%) of the women. Nearly one third of men and women (30.1\% and $33.9 \%$, respectively) underestimated their weight by at least $5 \%$, with average weight underestimates of $7.7 \pm 3.3 \mathrm{~kg}(16.9 \pm 7.3 \mathrm{lb})$ for men and $8.5 \pm 3.8 \mathrm{~kg}(18.7 \pm 8.4 \mathrm{lb})$ for women. 


\section{DISCUSSION}

National and international estimates of the prevalence of overweight and obesity are frequently based on BMI calculated from self-reported height and weight; however, evidence suggests the general population tends to inaccurately self-report their height and weight. ${ }^{6,7,9,12}$ Prior to this study, the accuracy of wheelchairs users' self-reports of height and weight had not been evaluated, which may compromise estimates of overweight and obesity prevalence in this group. Our results suggest similar trends of reporting errors as observed in the general population. ${ }^{7,8,12}$ Wheelchair users overestimate their height and underestimate their weight, resulting in significant differences between self-reported and measured BMI. We also observed a high level of individual variability in reporting errors for both height and weight, also found in the general population. For example, approximately one third of our sample underestimated their weight by an average of $\sim 8 \mathrm{~kg}(17.6 \mathrm{lb})$, while $11 \%$ of the sample overestimated their height by as much as $\sim 18 \mathrm{~cm}$ (7.0in).

This sample of wheelchair users also made larger errors reporting their height, weight, and BMI than a nationally representative sample of over 15,000 people $^{12}$ who overestimated their height by less than $1 \mathrm{~cm}$ (.39in) (vs $3.1 \mathrm{~cm}$ [1.2in] for our full sample) and underestimated their weight by less than $.75 \mathrm{~kg}(1.65 \mathrm{lb})$ (vs $1.7 \mathrm{~kg}$ [3.7in] for our full sample). This reflects a BMI underestimation of .59 units for the general population versus 1.7 units for our sample. Although the magnitude of the discrepancy was greater for our wheelchair users, the trends observed were similar in both samples as reporting errors for weight were associated with BMI and sex. Similar to the national sample, men in our sample made larger height overestimates, while women made larger weight underestimates. The pattern of errors observed in our sample and the general population was also similar across weight categories. Among this sample of wheelchair users, weight was overestimated in nomal weight men $(3.2 \mathrm{~kg}$ [7.0lb]) and underestimated in obese men $(2.9 \mathrm{~kg}$ [6.3lb]), whereas in women, those with healthy weight reported their weight accurately, and overweight or obese women underreported weight by 4.2 and $3.5 \mathrm{~kg}$, respectively $(9.3$ and $7.8 \mathrm{lb}$, respectively).

In terms of practical implications, $20 \%$ of our sample $(n=25)$ would be categorized in a heavier weight category based on BMI derived from measured versus self-reported height and weight, while $5.6 \%(\mathrm{n}=7)$ would be downgraded a weight category. This misclassification is notable given that current obesity estimates for people with disabilities derive exclusively from self-report. Consistent evidence shows that Americans with disabilities have significantly higher obesity rates than Americans without disabilities, ${ }^{16-18}$ and recent estimates indicate that $32 \%$ of Americans with a disability are obese and $66 \%$ are overweight or obese. ${ }^{18}$ Our study findings suggest that these current estimates may be lower than would be found if BMI was derived from a measured height and weight.

Furthermore, it is important to recognize that while BMI is extensively used for surveillance purposes to estimate obesity prevalence, it has been criticized as being an inaccurate predictor of body fat for some groups, including individuals with spinal cord injury (SCI) ${ }^{25-28}$ Evidence reveals that individuals with SCI have significantly higher body fat than matched samples (matched on age, weight, and height) without impairment, ${ }^{25,28}$ which has led to calls for lowering the BMI cut points for those with SCI. ${ }^{26,27}$ Therefore, future research should investigate whether other mobility impaired groups who use wheelchairs also have significantly higher body fat than age, sex, and BMI matched individuals.

\section{Study Limitations}

The generalizability of these results may be limited because of the following issues: (1) the data were obtained from a relatively small sample of wheelchair users who had volunteered 
to participate in an exercise intervention trial, (2) the study area was limited to the Midwest and therefore may not represent obesity rates in other regions, and (3) because of our exclusion criteria, those with BMIs $\geq 50$ were ineligible to participate and thus results cannot be extended to those at the higher end of the BMI range.

\section{CONCLUSIONS}

It is important to track obesity prevalence among people with disabilities, as consistent evidence indicates this group has significantly higher obesity rates than the general population and that people with disabilities experience higher rates of obesity-related comorbid conditions such as hypertension, diabetes, and cardiovascular disease. ${ }^{18,29,30}$ Notably, published national estimates of obesity prevalence in individuals with disabilities derive exclusively from self-reports, yet findings from this study argue for the need to obtain direct height and weight measures to more accurately track obesity prevalence among this group. The results suggest that wheelchair users are less accurate reporters of their weight and height than the general population, resulting in substantial misclassification of weight categories. These data, combined with evidence suggesting that the current BMI cut points for identifying overweight and obesity among those with SCI should be lowered, because these reference values do not adequately reflect body fat, and potentially compound the inaccurate assessment of disease risk for this group. Therefore, we recommend further study of this issue, because the impact of obesity may be even greater for the 54 million Americans who experience disability than it is in the general population in terms of negative consequences on health, function, and ability to maintain independence.

\section{Acknowledgments}

Supported by National Institute of Child Health and Human Development (NICHD)/National Institutes of Health (NIH) (grant no: R01 HD048628) and Frontiers: The Heartland Institute for Clinical and Translational Research (University of Kansas Medical Center's CTSA: UL1RR033179). The contents are solely the responsibility of the authors and do not necessarily represent the official views of the NIH, NICHD, or National Center on Medical Rehabilitation Research.

We thank James E. Grobe, $\mathrm{PhD}$ for his contribution designing and building the device used to obtain recumbent height measures.

\section{List of Abbreviations}

$\begin{array}{ll}\text { ANOVA } & \text { analysis of variance } \\ \text { BMI } & \text { body mass index } \\ \text { SCI } & \text { spinal cord injury }\end{array}$

\section{References}

1. Flegal KM, Carroll MD, Kit BK, Ogden CL. Prevalence of obesity and trends in the distribution of body mass index among US adults, 1999-2010. JAMA. 2012; 307:491-7. [PubMed: 22253363]

2. World Health Organization. [Accessed October 27, 2011] Obesity and overweight. 2011. Available at: http://www.who.int/mediacentre/factsheets/fs311/en/index.html

3. Flegal KM, Graubard BI, Williamson DF, Gail MH. Cause-specific excess deaths associated with underweight, overweight, and obesity. JAMA. 2007; 298:2028-37. [PubMed: 17986696]

4. National Heart, Lung, and Blood Institute. Clinical Guidelines on the Identification, Evaluation, and Treatment of Overweight and Obesity in Adults-The Evidence Report. Obes Res. 1998; 6(Suppl 2): 51S-209S. [PubMed: 9813653]

5. John U, Hanke M, Grothues J, Thyrian J. Validity of overweight and obesity in a nation based on self-report versus measurement device data. Eur J Clin Nutr. 2006; 60:372-7. [PubMed: 16278688] 
6. Rowland ML. Self-reported weight and height. Am J Clin Nutr. 1990; 52:1125-33. [PubMed: 2239790]

7. Gorber SC, Tremblay M, Moher D, Gorber B. A comparison of direct vs. self-report measures for assessing height, weight, and body mass index: a systematic review. Obes Rev. 2007; 8:307-26. [PubMed: 17578381]

8. Nawaz H, Chan W, Abdulrahman M, Larson D, Katz DL. Self-reported weight and height: implications for obesity research. Am J Prev Med. 2001; 20:294-8. [PubMed: 11331120]

9. Kuczmarski MA, Kuczmarski RJ, Najjar M. Effects of age on validity of self-reported height, weight, and body mass index: findings from the third National Health and Nutrition Examination Survey, 1988-1994. J Am Diet Assoc. 2001; 101:28-34. [PubMed: 11209581]

10. Ziebland S, Thorogood M, Fuller A, Muir J. Desire for the body normal: body image and discrepancies between self reported and measured height and weight in a British population. $\mathrm{J}$ Epidemiol Community Health. 1996; 50:105-6. [PubMed: 8762365]

11. Fillenbaum GG, Kuchibhatla MN, Whitson HE, et al. Accuracy of self-reported height and weight in a community-based sample of older African Americans and Whites. J Gerontol A Biol Sci Med Sci. 2010; 65:1123-9. [PubMed: 20530243]

12. Stommel M, Schoenborn CA. Accuracy and usefulness of BMI measures based on self-reported weight and height: findings from the NHANES and NHIS 2001-2006. BMC Public Health. 2009; 9:421. [PubMed: 19922675]

13. Gillim RF, Sempos CT. Ethnic variation in validity of classification of overweight and obesity using self-reported weight and height in American women and men: the Third National Health and Nutrition Examination Survey. Nutr J. 2005; 4:27-34. [PubMed: 16209706]

14. Dekkers JC, van Wier MF, Hendriksen IJ, Twisk JW, van Mechelen W. Accuracy of self-reported body weight, height and waist circumference in a Dutch overweight working population. BMC Medical Research Methodology. 2008; 8:69. [PubMed: 18957077]

15. Elgar FJ, Stewart J. Validity of self-report screening for overweight and obesity. Can J Public Health. 2008; 99:423-7. [PubMed: 19009930]

16. Weil E, Wachterman M, McCarthy EP, et al. Obesity among adults with disabling conditions. JAMA. 2002; 288:1265-8. [PubMed: 12215134]

17. Centers for Disease Control and Prevention. State-specific prevalence of obesity among adults with disabilities- eight states and the District of Columbia, 1998-1999. MMWR Morb Mortal Wkly Rep. 2002; 51:805-8. [PubMed: 12269468]

18. Altman, B.; Bernstein, A. Disability and health in the United States, 2001-2005. Hyattsville: National Center for Health Statistics; 2008. p. 34-6.

19. Graham CL, Mann JR. Accessibility of primary care physician practice sites in South Carolina for people with disabilities. Disabil Health J. 2008; 1:209-14. [PubMed: 21122731]

20. Froehlich-Grobe K, Nary DE, VanSciver A, Lee J, Little TD. Measuring height without a stadiometer: empirical investigation of four height estimates among wheelchair users. Am J Phys Med Rehabil. 2011; 90:658-66. [PubMed: 21681063]

21. Garshick E, Ashba J, Tun CG, Lieberman SL, Brown R. Assessment of stature in spinal cord injury. J Spinal Cord Med. 1997; 20:36-42. [PubMed: 9097254]

22. Nary DE, Froehlich-Grobe K, Aaronson L. Recruitment issues in a randomized controlled exercise trial targeting wheelchair users. Contemp Clin Trials. 2011; 32:188-95. [PubMed: 21035565]

23. Patterson, RM., inventor. Adjustable T Square. U.S. patent 4,525,933. Jul 2. 1985

24. Bland JM, Altman DG. Statistical methods for assessing agreement between two methods of clinical measurement. Lancet. 1986; 327:307-10. [PubMed: 2868172]

25. Jones LM, Legge M, Goulding A. Healthy body mass index values often underestimate body fat in men with spinal cord injury. Arch Phys Med Rehabil. 2003; 84:1068-71. [PubMed: 12881836]

26. Buchholz AC, Bugaresti JM. A review of body mass index and waist circumference as markers of obesity and coronary heart disease risk in persons with chronic spinal cord injury. Spinal Cord. 2005; 43:513-8. [PubMed: 15824757]

27. Laughton GE, Buchholz AC, Martin Ginis KA, Goy RE. SHAPE SCI Research Group. Lowering body mass index cutoffs better identifies obese persons with spinal cord injury. Spinal Cord. 2009; 47:757-62. [PubMed: 19350042] 
28. Edwards LA, Bugaresti JM, Buchholz AC. Visceral adipose tissue and the ratio of visceral to subcutaneous adipose tissue are greater in adults with than in those without spinal cord injury, despite matching waist circumferences. Am J Clin Nutr. 2008; 87:600-7. [PubMed: 18326597]

29. Rasch EK, Hochberg MC, Magder L, Magaziner J, Altman BM. Health of community-dwelling adults with mobility limitations in the United States: prevalent health conditions. Part I Arch Phys Med Rehabil. 2008; 89:210-8.

30. Reichard A, Stolzle H, Fox MH. Health disparities among adults with physical disabilities or cognitive limitations compared to individuals with no disabilities in the United States. Disabil Health J. 2011; 4:59-67. [PubMed: 21419369] 


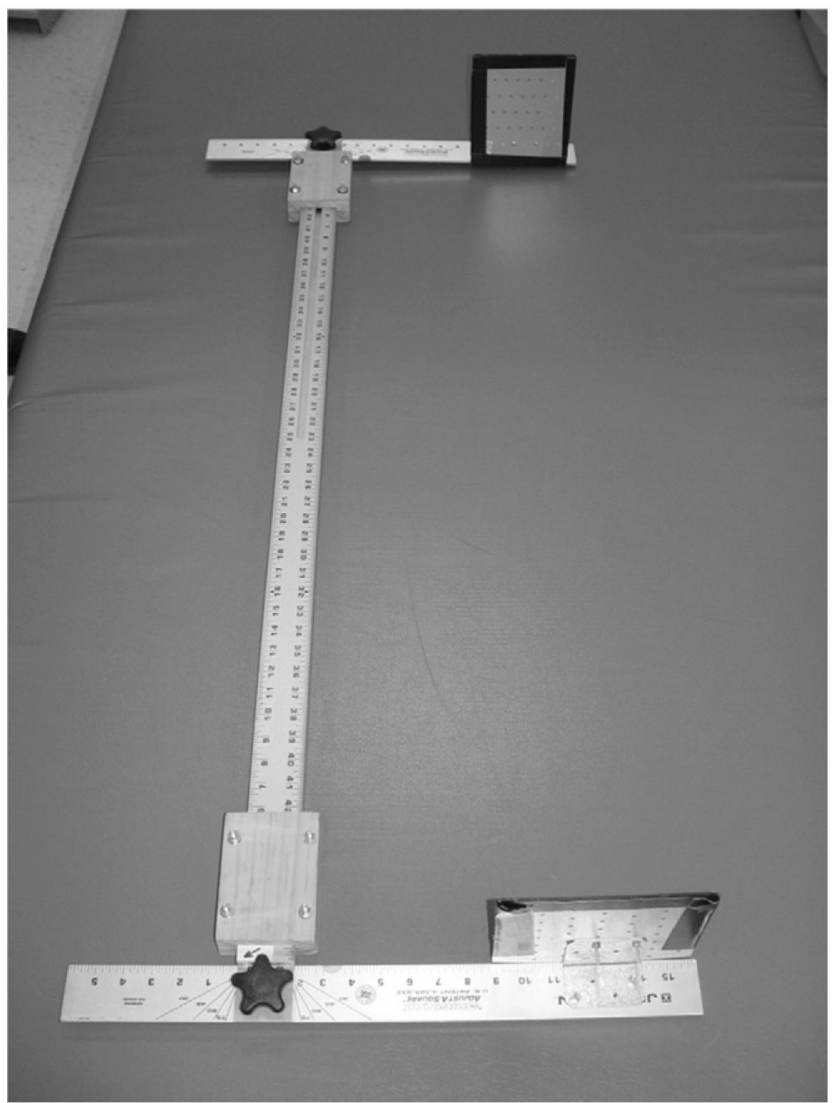

Fig. 1.

Anthropometer built to measure recumbent height. 


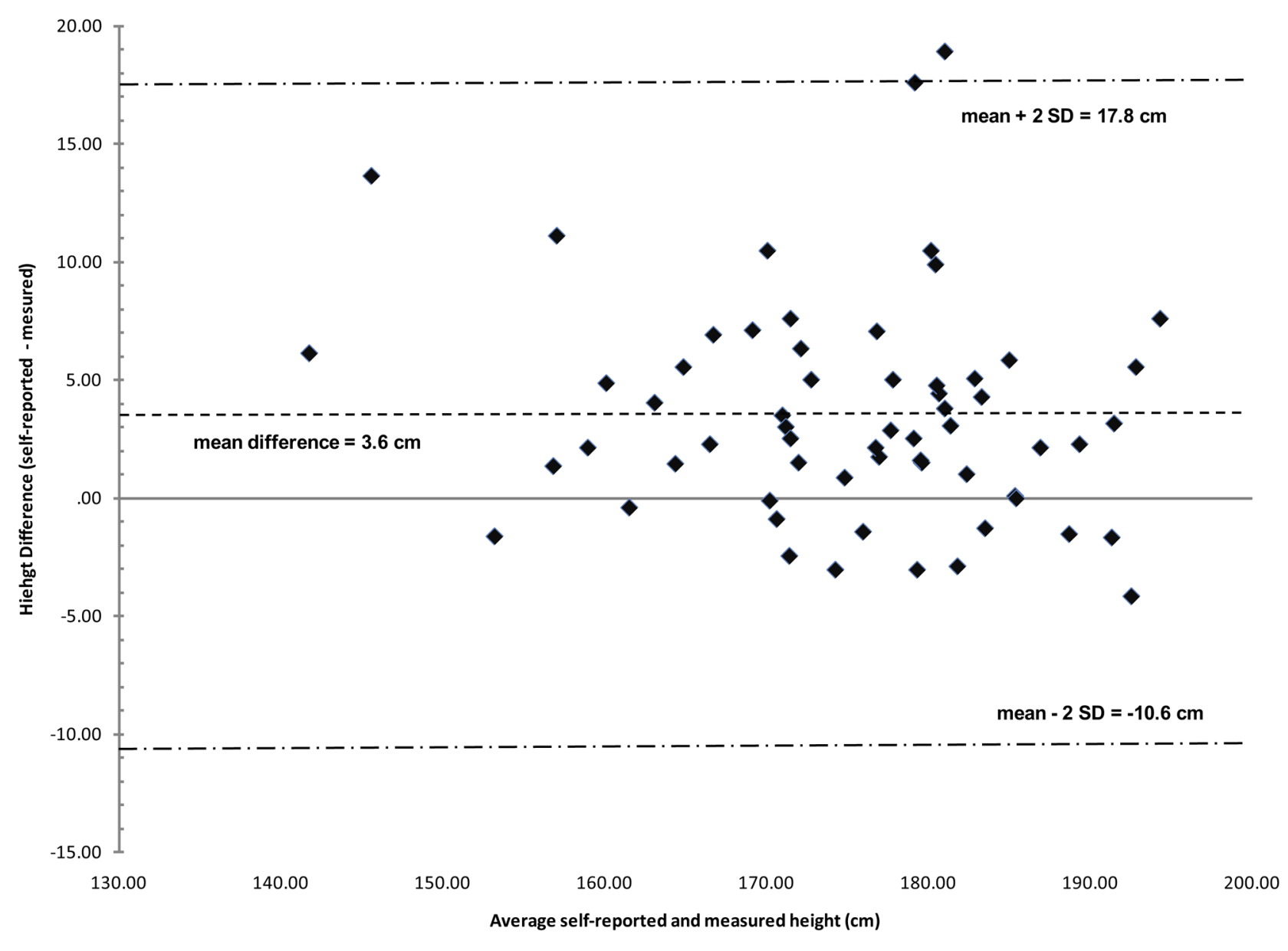

Fig. 2.

Self-reported versus measured height in wheelchair users who are men $(n=63)$. 


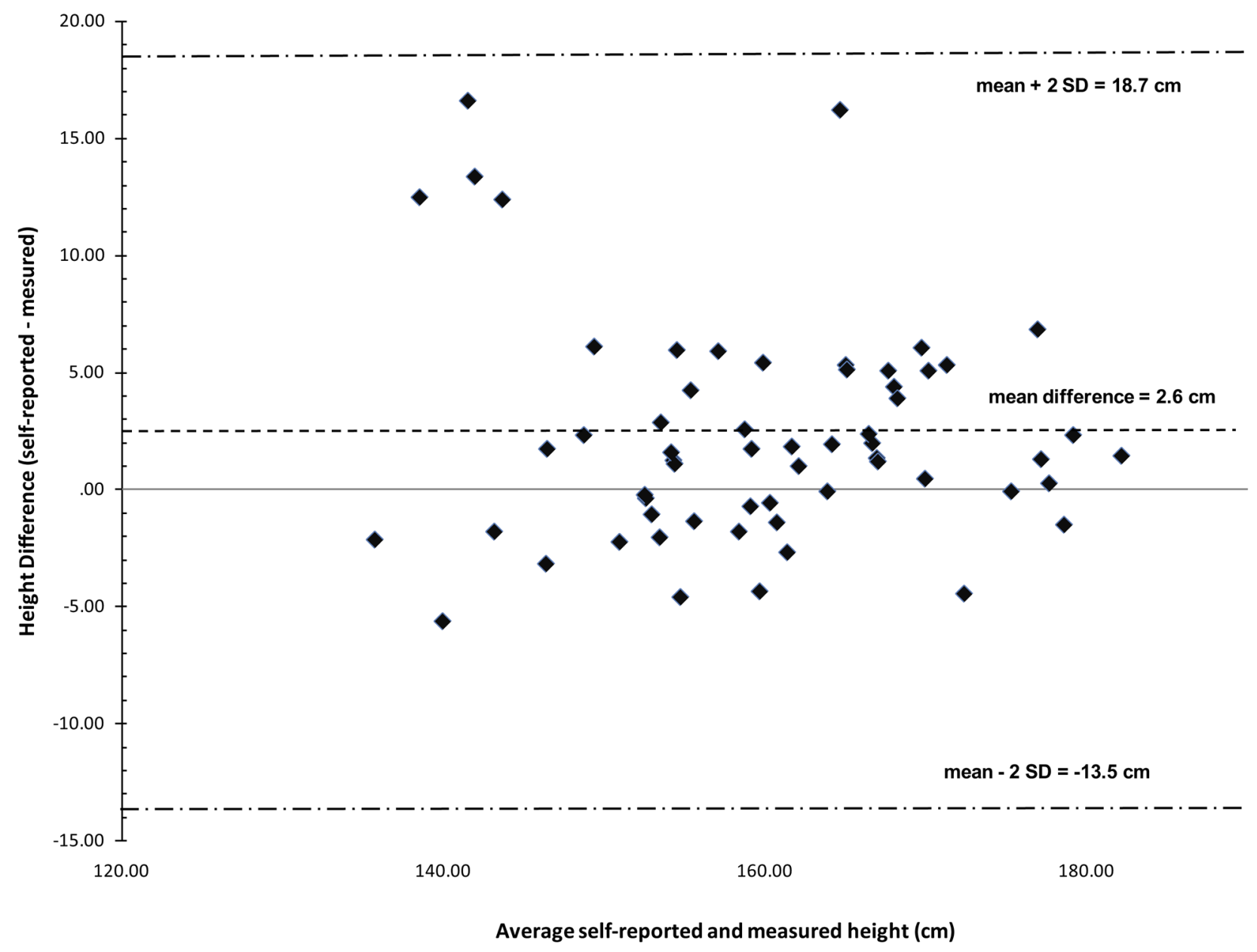

Fig. 3.

Self-reported versus measured height in wheelchair users who are women $(n=62)$. 




Fig. 4.

Self-reported versus measured weight in wheelchair users who are men $(n=63)$. 


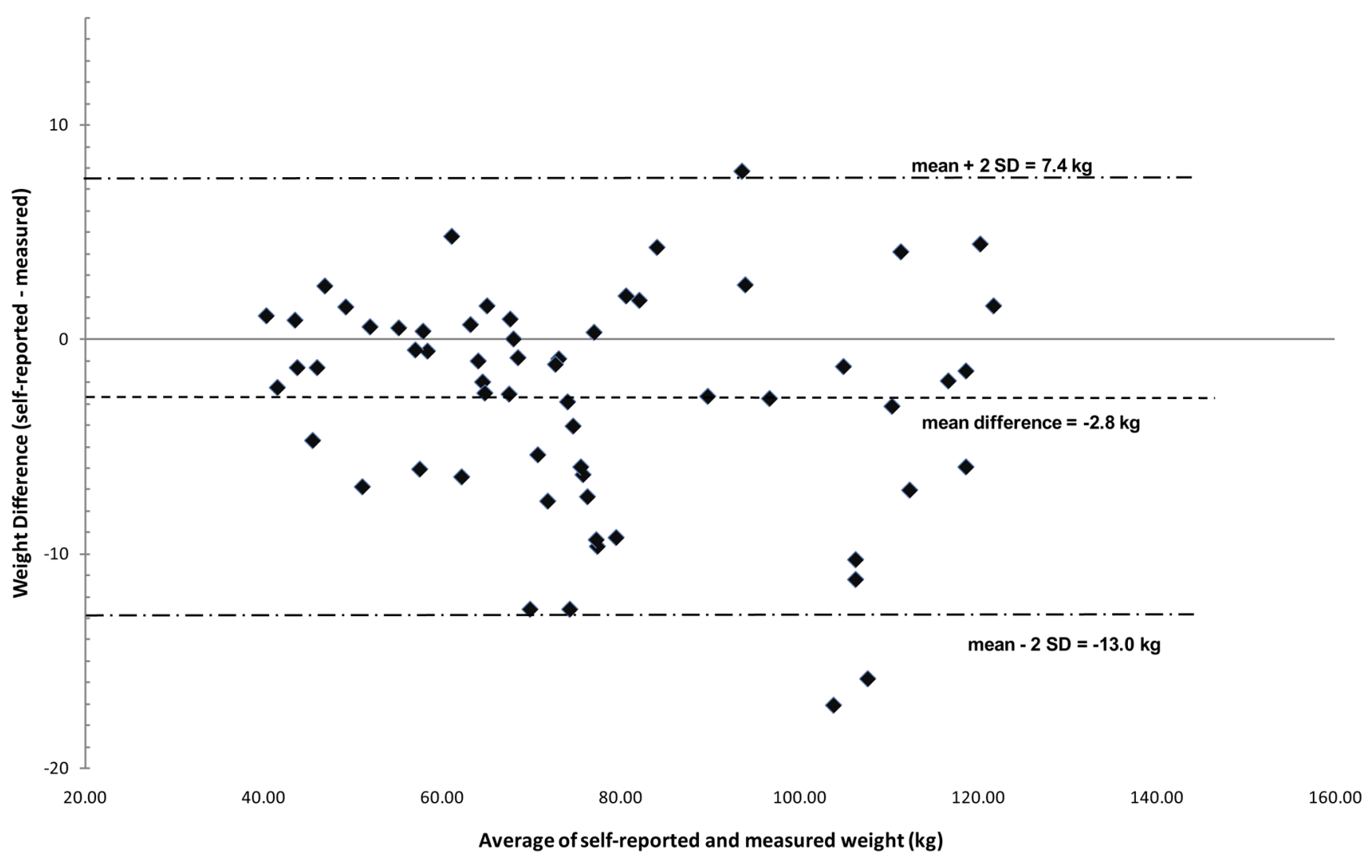

Fig. 5.

Self-reported versus measured weight in wheelchair users who are women $(n=62)$. 


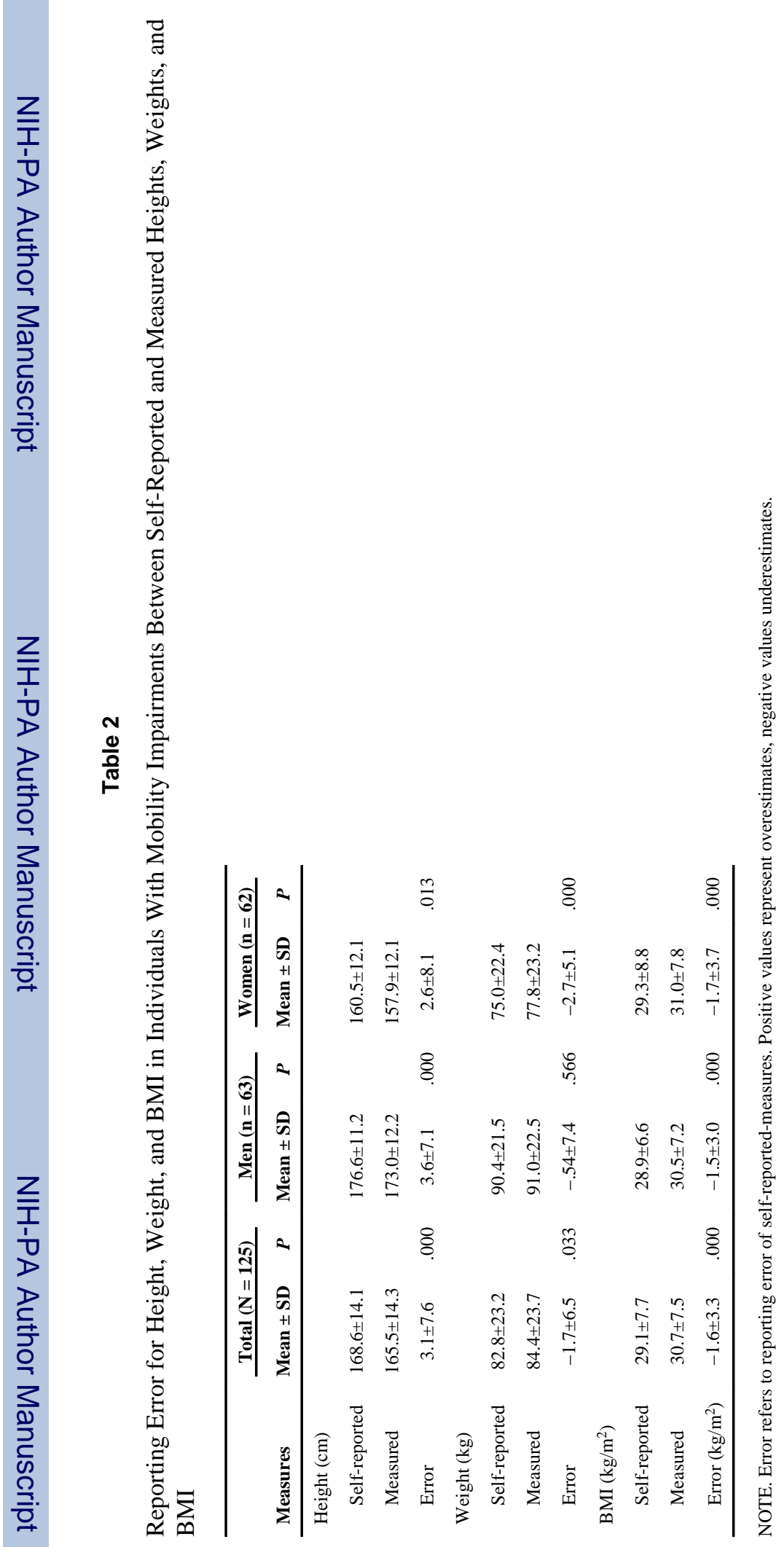


